older surgeons and those in practice longer were less likely to refer to guidelines in the provision of patient care. Older surgeons were also more hesitant to incorporate findings from database research into their clinical practice. The authors suggest that health services researchers address how new data are presented to influence clinical practice patterns.

This study identifies a number of critical issues in the way clinical research is performed in thoracic surgery. Although many respondents were academic surgeons participating in the Thoracic Surgery Outcomes Research Network, some expressed doubt that the type of research commonly performed is truly moving the field forward. Respondents highlighted randomized controlled trials (RCTs) as the standard in clinical research, but the reality remains that there are many more important clinical questions to be answered than can feasibly be studied through RCTs. Perhaps most notably, despite evidence of improved outcomes after guideline-concordant care in non-small cell lung cancer, ${ }^{2-4}$ more experienced surgeons tended to prefer their own experience and that of thought leaders to guidelines considered outdated and ill-equipped for use in the current era of personalized medicine.

Fortunately, the term health services research represents much more than retrospective analyses of large administrative databases. Because it is not feasible to perform RCTs for every important clinical question, we can instead make more robust use of the many research designs and analytic techniques available in the health services research toolbox. We should harness collaborative groups to design prospective multicenter cohort studies that include clinically important data points. Inclusion of factors important to treatment selection in datasets will allow for application of propensity-based analytic techniques to limit the influence of selection bias on study results. Shemanski and colleagues ${ }^{1}$ demonstrate the power of qualitative data analysis, which can be used in tandem with welldesigned prospective studies to understand the interactions between individual patient characteristics and treatment selection decisions among expert surgeons. A combination of clinical expertise and robust data analysis can then be translated into evidence-based clinical guidelines and decision tools that improve patient care. That is health services research at its best.

\section{References}

1. Shemanski K, Farias A, Leiu D, Kim AW, Wightman S, Atay SM, et al. Understanding thoracic surgeons' perceptions of administrative database analyses and guidelines in clinical decision-making. J Thorac Cardiovasc Surg. 2021;161:807-16.e1.

2. Ahmed HZ, Liu Y, O'Connell K, Ahmed MZ, Cassidy RJ, Gillespie TW, et al Guideilne-concordant care improves overall survival for locally advanced nonsmall-cell lung carcinoma patients: a national cancer database analysis. Clin Lung Cancer. 2017;18:4691-700.

3. Stokes SM, Massarweh NN, Stringham JR, Varghese TK Jr. Clinical-pathologic correlation and guideline concordance in resectable non-small cell lung cancer. Ann Thor Surg. 2019;108:837-44.

4. Samson P, Crabtree T, Broderick S, Kreisel D, Krupnick AS, Patterson GA, et al. Quality measures in clinical stage I non-small cell lung cancer: improved performance is associated with improved survival. Ann Thor Surg. 2017;103:303-11.

\title{
Commentary: Rush to judgment: Surgeons' thinking, fast and slow
}

\section{Andrea S. Wolf, MD, MPH}

Surgeons are generally decisive people with no shortage of opinions, yet we can learn something from exploring where these opinions originate. What is most novel about the study

From the New York Mesothelioma Program and Department of Thoracic Surgery, The Icahn School of Medicine at Mount Sinai, New York, NY.

Disclosures: The author reported no conflicts of interest.

The Journal policy requires editors and reviewers to disclose conflicts of interest and to decline handling or reviewing manuscripts for which they may have a conflict of interest. The editors and reviewers of this article have no conflicts of interest.

Received for publication Sept 25, 2020; revisions received Sept 25, 2020; accepted for publication Sept 25, 2020; available ahead of print Oct 5, 2020.

Address for reprints: Andrea S. Wolf, MD, MPH, New York Mesothelioma Program, Department of Thoracic Surgery, The Icahn School of Medicine at Mount Sinai, 1190 Fifth Ave, Box 1023, New York, NY 10029 (E-mail: andrea.wolf@ mountsinai.org).

J Thorac Cardiovasc Surg 2021;161:820-1

$0022-5223 / \$ 36.00$

Copyright (c) 2020 by The American Association for Thoracic Surgery

https://doi.org/10.1016/j.jtcvs.2020.09.113

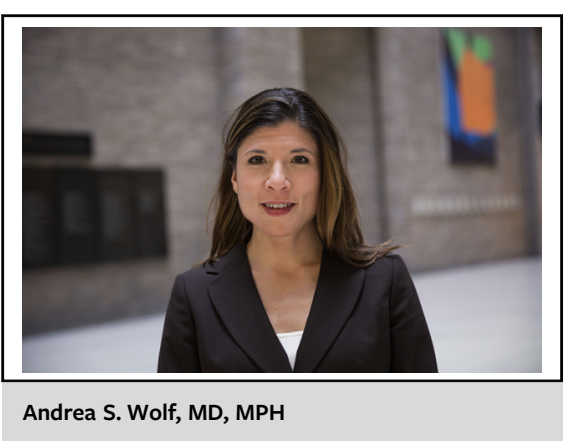

CENTRAL MESSAGE

The psychology of decision making can help surgeons balance evidence-based practice with practical evidence in their skepticism of database analyses and idealism of randomized controlled trials. 
by Shemanski and colleagues ${ }^{1}$ is its qualitative analysis that allows for examination of subtle but important findings about how surgeons factor database studies and consensus guidelines into practice. ${ }^{1}$ The authors' mixed-methods approach uses inductive reasoning to tease out 5 themes regarding surgeons' perceptions of database studies and clinical guidelines.

The use of heuristics to aid decision making (based mostly on intuition and experience) is subject to overconfidence, inconsistencies, and biases that not only result in error, but also lead to overcorrection and continued flawed judgment. ${ }^{2}$ Most surgeons use database analyses to support plans they have already made. Daniel Kahneman, ${ }^{3}$ a Nobel Prize winner and Princeton professor explains in his book, Thinking, Fast and Slow, that errors result from the natural human tendency to provide too much importance to familiar (read: anecdotal) experiences; that is, we rely too heavily on the faster intuitive decision-making process and not enough on the slower calculated process that applies rules and statistics.

That said, like the mathematical psychologists who were subjects in Tversky and Kahneman's original 1969 experiment in the psychology of decision making and judgment ${ }^{2}$ the surgeons interviewed for the current study were well aware of these issues. In fact, a recurring concern among surgeons interviewed was the lack of evidence from gold-standard studies-randomized controlled trials (RCTs) - and the limitations of database analyses in providing answers to important clinical questions. This leads to the next fallacy of a dogmatic approach: Setting the RCT as the bar for which we can use evidence in clinical decision making. This extreme viewpoint, the apparent alternative to using anecdotes to guide practice, has its own pitfalls. A tongue-in-cheek systematic review documenting no RCT evaluating parachutes for preventing death when jumping out of airplanes inspired a recent trial that showed no benefit. ${ }^{4,5}$ In the field of surgery, RCTs are rare due to lack of equipoise at an individual level, long duration (that may result in rapid external developments upending interpretation), and difficulty accruing patients. ${ }^{6}$ These challenges complicated the conduct of the well-designed Cancer and Leukemia Group B/Alliance for Clinical Trials in Oncology (CALGB/ALLIANCE 140503) trial comparing lobectomy to sublobar resection for sub-2-cm non-small cell lung cancer (Clinical Trials.gov identifier: NCT00499330), which, after halving its enrollment goal, accrued patients over 10 years and is expected to yield results in 2021, 13 years after opening in 2007.

Surgeons recognize that database analyses can be used in context and RCTs are ideal but rare. The problem that remains is how best to design studies that guide clinical practice in the face of these constraints. In response, the Institute of Medicine called for new research methods to enhance the speed and reliability with which evidence is developed ${ }^{7}$ and the American Society of Clinical Oncology recently lauded the untapped potential of observational studies. ${ }^{8}$ The solution might be creative, but rigorous research approaches such as the international multicenter prospective cohort study the Initiative for Early Lung Cancer Research on Treatment, ${ }^{6}$ with the goal of helping surgeons think, fast and slow, more effectively.

\section{References}

1. Shemanski KA, Farias A, Lieu D, Kim AW, Wightman S, Atay SM, et al. Understanding thoracic surgeons' perceptions of administrative database analyses and guidelines in clinical decision-making. J Thorac Cardiovasc Surg. 2021;161: 807-16.e1.

2. Tversky A, Kahneman D. Belief in law of small numbers. Psychol Bull. 1971;76:105.

3. Kahneman D. Thinking, Fast and Slow. 1st ed. New York, NY: Farrar, Straus and Giroux; 2011.

4. Smith GC, Pell JP. Parachute use to prevent death and major trauma related to gravitational challenge: systematic review of randomised controlled trials. BMJ. 2003;327:1459-61.

5. Yeh RW, Valsdottir LR, Yeh MW, Shen C, Kramer DB, Strom JB, et al. Parachute use to prevent death and major trauma when jumping from aircraft: randomized controlled trial. BMJ. 2018:363:k5094.

6. Flores R, Taioli E, Yankelevitz DF, Becker BJ, Jirapatnakul A, Reeves A, et al Initiative for early Lung cancer research on treatment: development of study design and pilot implementation. J Thorac Oncol. 2018;13:946-57.

7. Olsen L, Aisner D, McGinnis JM, eds. The Learning Healthcare System: Workshop Summary. Washington, DC: National Academies Press; 2007.

8. Visvanathan K, Levit LA, Raghavan D, Hudis CA, Wong S, Dueck A, et al. Untapped potential of observational research to inform clinical decision making: American Society of Clinical Oncology Research Statement. J Clin Oncol. 2017;35:1845-54 